\title{
Evaluation of aortic valve prolapse in ventricular septal defect
}

\author{
SAMUEL MENAHEM, JENNIFER A JOHNS, STEFANO DEL TORSO, \\ TIOW H GOH, ALEXANDER W VENABLES \\ From the Department of Cardiology, Royal Children's Hospital, Melbourne, Australia
}

SUMMARY Angiographic criteria for the recognition of aortic valve prolapse in isolated ventricular septal defect were based on the degree of aortic cusp deformity and the presence or absence of aortic regurgitation. Ninety eight consecutive patients with isolated perimembranous or infundibular ventricular septal defects who were catheterised and had aortography performed were reviewed. They included five with postoperative ventricular septal defects and three with additional mild right ventricular outflow tract obstruction. Eighteen were found to have aortic valve prolapse. Although eight of the 18 were noted to have aortic regurgitation angiographically, only three had an early diastolic murmur. Only eight of the 18 patients had cross sectional echocardiographic findings suggestive of prolapse. All of these had at least moderate prolapse angiographically. Cross sectional echocardiography was found to be insensitive in diagnosing mild degrees of aortic valve prolapse. A trend towards a decreasing left to right shunt was noted as the degree of aortic valve prolapse increased. Spontaneous decrease in the size of a ventricular septal defect may be due to unrecognised aortic valve prolapse without clinical evidence of aortic regurgitation.

Van Praagh and McNamara have described multiple mechanisms for aortic valve prolapse in ventricular septal defect. ${ }^{1}$ They and others have suggested that an infundibular (supracristal) ventricular septal defect leads to a lack of anatomical support of the aortic valve, the right coronary cusp and sinus of Valsalva being without conal muscular support. ${ }^{23}$ In perimembranous (infracristal) ventricular septal defect the defect typically lies between approximately half of each leaflet of the right and noncoronary cusps. There is probably also an abnormal aortic valve with a defective commissure, usually between the right and the non-coronary cusps, with subsequent poor aortic leaflet apposition during diastole. With infundibular defects of the muscular interventricular septum there is often considerable herniation of the right coronary cusp, in contrast to the involvement of the right and noncoronary cusps in perimembranous defects. ${ }^{1-3}$

Requests for reprints to Dr Samuel Menahem, Department of Cardiology, Royal Children's Hospital, Parkville, Victoria 3052, Australia.

Accepted for publication 2 June 1986
There may also be lateral movement of the aortic valve and sinus to the right during rapid ejection of blood from the left ventricle to the aortic root.

In addition, the intra-aortic pressure during diastole is said to force the unsupported aortic valve annulus towards the right ventricle with elongation of the free margin of the aortic cusp and resultant incompetence. Further, a Venturi effect may be produced by the systolic jet across the ventricular septal defect. ${ }^{1-4}$

Aortic valve prolapse may lead to progressive aortic regurgitation, ${ }^{5}$ increasing the volume load of the left ventricle. The development of aortic valve prolapse has been recognised clinically by the presence of aortic regurgitation in ventricular septal defect, ${ }^{5-7}$ though the real frequency of aortic valve prolapse in ventricular septal defect remains unclear.

In the present study we aimed to document aortic valve prolapse in association with ventricular septal defect as demonstrated by aortography, ${ }^{268}$ and to establish whether such aortic valve prolapse may be diagnosed by cross sectional echocardiography. 910

Indications for surgical intervention remain 
unclear ${ }^{11}$ but a careful assessment of the severity of aortic valve prolapse and the degree of related aortic regurgitation may facilitate the decision making process.

\section{Patients and methods}

The clinical data and angiograms of patients with isolated infundibular and perimembranous ventricular septal defect who underwent cardiac catheterisation from January 1982 to January 1984 were reviewed. These patients were studied because of clinical evidence of an appreciable left to right shunt or persistent radiological evidence of cardiomegaly. Ninety eight patients, all white except for five of Chinese origin, were included in the study if they underwent both biplane left ventricular and aortic root angiography. Their ages ranged from two weeks to 15 years; $37 \%$ were less than one year old. Pulmonary to systemic flow ratios (Qp:Qs) were calculated from oxygen saturation measurements. Most studies were performed under endotracheal anaesthesia with controlled respiration.

Cross sectional echocardiography was carried out on most patients at review by means of a real time mechanical scanner (Advanced Technology Laboratories) with a 3.5 or $5.0 \mathrm{MHz}$ transducer before or during admission for cardiac catheterisation. Standard parasternal, apical, and subxiphoid views of the left ventricle and aorta were obtained.

\section{AORTOGRAPHIC CRITERIA USED TO CLASSIFY AORTIC VALVE PROLAPSE}

Grading of aortic valve prolapse was defined as follows and as shown in figs 1-4:

Grade I.-Mild aortic valve deformity with a nipple like protrusion of part of the cusp arising from slight prolapse of the leaflet into the ventricular septal defect. No aortic regurgitation (fig 1).

Grade IIa.-Moderate deformity of one or more cusps with further prolapse into the ventricular septal defect and resultant abnormal opening of involved leaflet(s). No aortic regurgitation (fig 2).

Grade IIb.-As for grade IIa but with aortic regurgitation (fig 3).

Grade III. - Severe aortic valve deformity with one or more cusp(s) apparently tethered to margin of the ventricular septal defect and with resultant
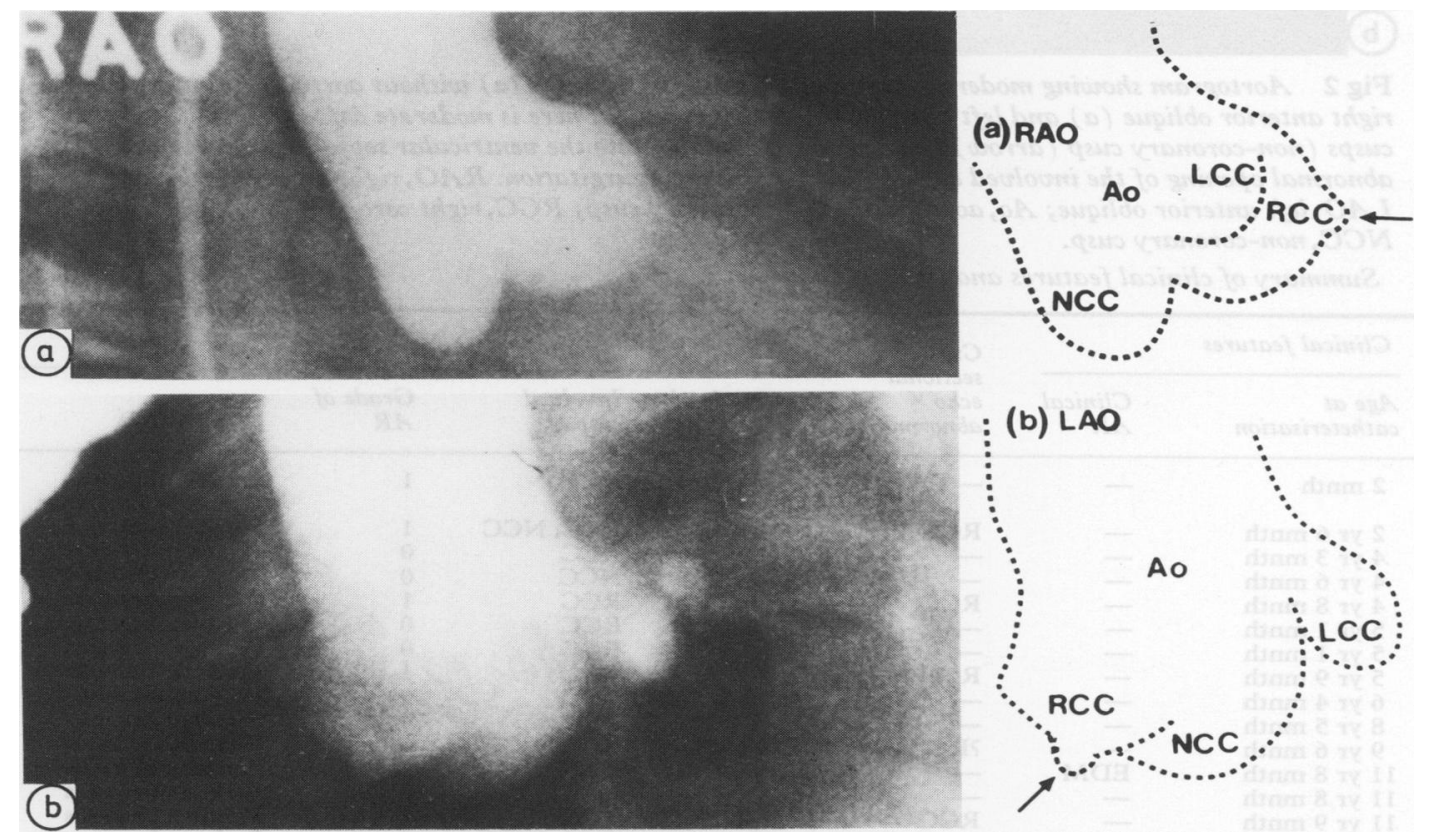

Fig 1 Aortogram showing aortic valve prolapse (grade I) right anterior oblique (a) and left anterior oblique (b) views. There is mild aortic valve deformity with a nipple like protrusion of part of the cusp arising as a result of slight prolapse of the leaflet (right coronary cusp (arrow)) into the ventricular septal defect. Ao, aorta; LCC, left coronary cusp; NCC, non-coronary cusp; RCC, right coronary cusp; $R A O$, right anterior oblique; LAO, left anterior oblique. 

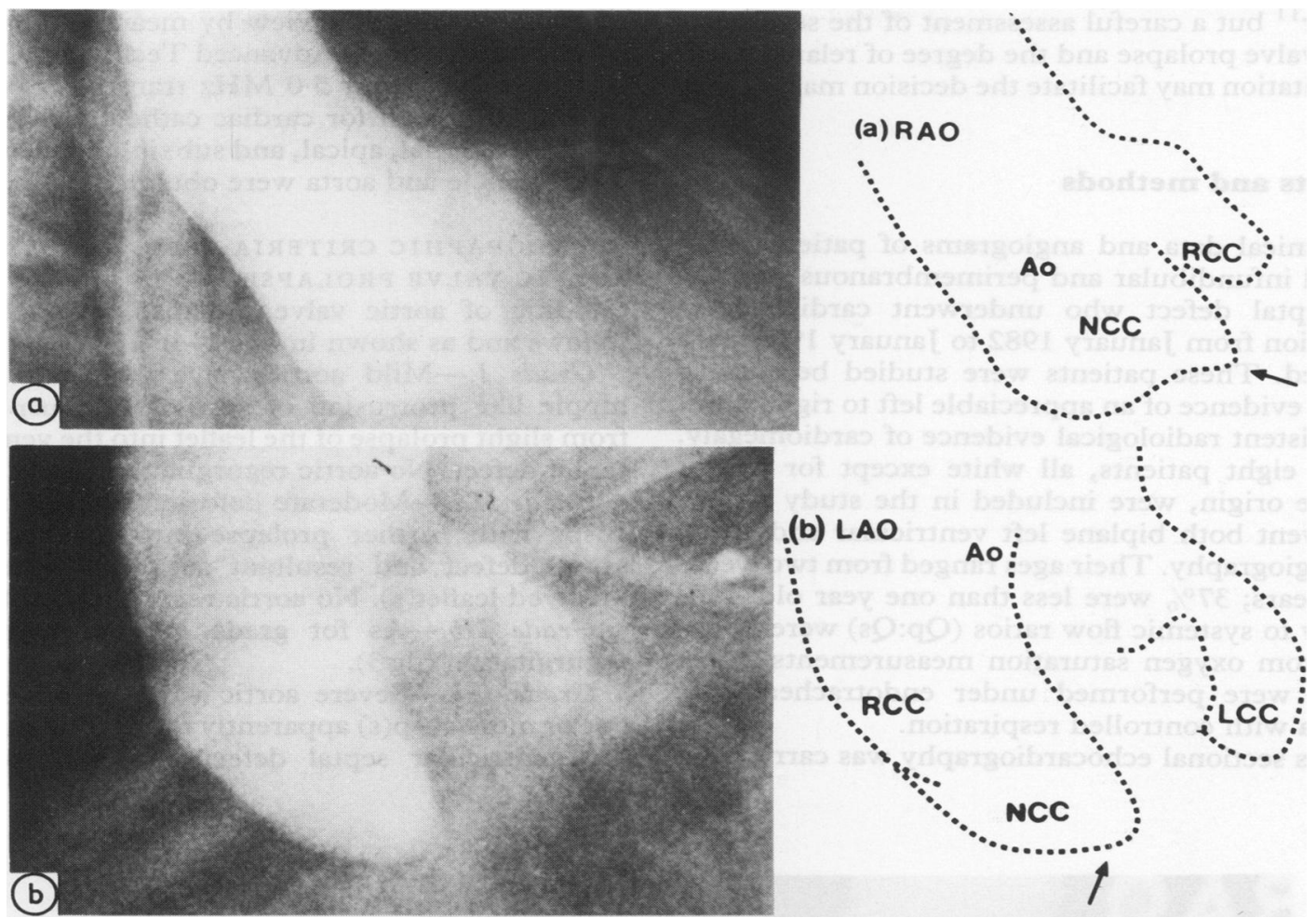

(b)

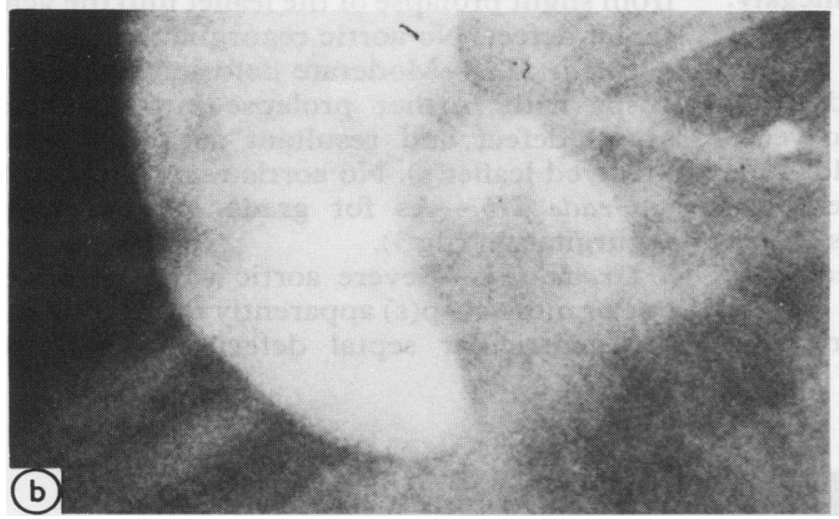

Fig 2 Aortogram showing moderate aortic valve prolapse (grade IIa) without aortic regurgitation in the right anterior oblique (a) and left anterior oblique (b) views. There is moderate deformity of one or more cusps (non-coronary cusp (arrow)) as a result of prolapse into the ventricular septal defect and hence abnormal opening of the involved cusp $(s)$, and no aortic regurgitation. $R A O$, right anterior oblique; $L A O$, left anterior oblique; Ao, aorta; LCC, left coronary cusp; RCC, right coronary cusp; NCC, non-coronary cusp.

Table 1 Summary of clinical features and investigations

\begin{tabular}{|c|c|c|c|c|c|c|c|c|}
\hline \multirow[b]{2}{*}{$\begin{array}{l}\text { Case } \\
\text { No }\end{array}$} & \multicolumn{2}{|l|}{ Clinical features } & \multirow{2}{*}{$\begin{array}{l}\text { Cross } \\
\text { sectional } \\
\text { echo } \\
\text { abnormality }\end{array}$} & \multicolumn{4}{|c|}{ Catheter findings } & \multirow{2}{*}{ 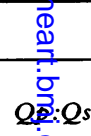 } \\
\hline & $\begin{array}{l}\text { Age at } \\
\text { catheterisation }\end{array}$ & $\begin{array}{l}\text { Clinical } \\
A R\end{array}$ & & $\begin{array}{l}\text { Grade of } \\
A V P\end{array}$ & $\begin{array}{l}\text { Involved } \\
\text { cusp }\end{array}$ & $\begin{array}{l}\text { Grade of } \\
A R\end{array}$ & Site of VSD & \\
\hline 1 & 2 mnth & 一 & - & IIb & NCC & 1 & $\begin{array}{l}\text { Perimembranous } \\
\quad+\text { mid-muscular }\end{array}$ & 色1 \\
\hline $\begin{array}{r}2 \\
3 \\
4 \\
5 \\
6 \\
7 \\
8 \\
9 \\
10 \\
11 \\
12 \\
13 \\
14 \\
15 \\
16 \\
17 \\
18\end{array}$ & $\begin{array}{l}2 \text { yr } 6 \text { mnth } \\
4 \text { yr } 3 \text { mnth } \\
4 \text { yr } 6 \text { mnth } \\
4 \text { yr } 8 \text { mnth } \\
5 \text { yr } 1 \text { mnth } \\
5 \text { yr } 1 \text { mnth } \\
5 \text { yr } 9 \text { mnth } \\
6 \text { yr } 4 \text { mnth } \\
8 \text { yr } 5 \text { mnth } \\
9 \text { yr } 6 \text { mnth } \\
11 \text { yr } 8 \text { mnth } \\
11 \text { yr } 8 \text { mnth } \\
11 \text { yr } 9 \text { mnth } \\
12 \text { yr } 11 \text { mnth } \\
14 \text { yr } 3 \text { mnth } \\
7 \text { yr } 2 \text { mnth } \\
9 \text { yr } 2 \text { mnth }\end{array}$ & $\begin{array}{l}= \\
= \\
= \\
= \\
= \\
\bar{E} \\
= \\
= \\
\overline{E D M} \\
\text { EDM }\end{array}$ & $\begin{array}{l}\mathrm{RCC} \\
\overline{\overline{R C C}} \\
\overline{-} \\
\mathrm{RCC} \\
\overline{-} \\
\text { ?RCC, NCC } \\
\overline{-} \\
\text { RCC } \\
\text { RCC } \\
\text { RCC } \\
-\end{array}$ & $\begin{array}{l}\text { IIb } \\
\text { IIa } \\
\text { IIa } \\
\text { IIb } \\
\text { IIa } \\
\text { I } \\
\text { IIb } \\
\text { I } \\
\text { I } \\
\text { IIa } \\
\text { III } \\
\text { I } \\
\text { III } \\
\text { IIIa } \\
\text { IIa } \\
\text { III } \\
\text { IIb }\end{array}$ & $\begin{array}{l}\text { RCC, NCC } \\
\text { RCC } \\
\text { NCC } \\
\text { RCC } \\
\text { RCC } \\
\text { RCC } \\
\text { RCC } \\
\text { RCC } \\
\text { RCC } \\
\text { RCC, NCC } \\
\text { NCC } \\
\text { RCC } \\
\text { RCC } \\
\text { RCC, NCC } \\
\text { NCC } \\
\text { RCC } \\
\text { RCC }\end{array}$ & $\begin{array}{l}1 \\
0 \\
0 \\
1 \\
0 \\
0 \\
1 \\
0 \\
0 \\
0 \\
3 \\
0 \\
1 \\
0 \\
0 \\
5 \\
3\end{array}$ & $\begin{array}{l}\text { Perimembranous } \\
\text { Perimembranous } \\
\text { Perimembranous } \\
\text { Perimembranous } \\
\text { Perimembranous } \\
\text { Perimembranous } \\
\text { Perimembranous } \\
\text { Perimembranous } \\
\text { Perimembranous } \\
\text { Perimembranous } \\
\text { Perimembranous } \\
\text { Perimembranous } \\
\text { Perimembranous } \\
\text { Perimembranous } \\
\text { Perimembranous } \\
\text { Infundibular } \\
\text { Infundibular }\end{array}$ & 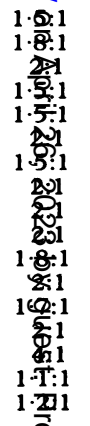 \\
\hline
\end{tabular}

RCC, right coronary cusp; AVP, aortic valve prolapse; NCC, non-coronary cusp; AR, aortic regurgitation; EDM, early diastolic mu再ur; VSD, ventricular septal defect; $Q p$, pulmonary flow; Qs, systemic flow. 

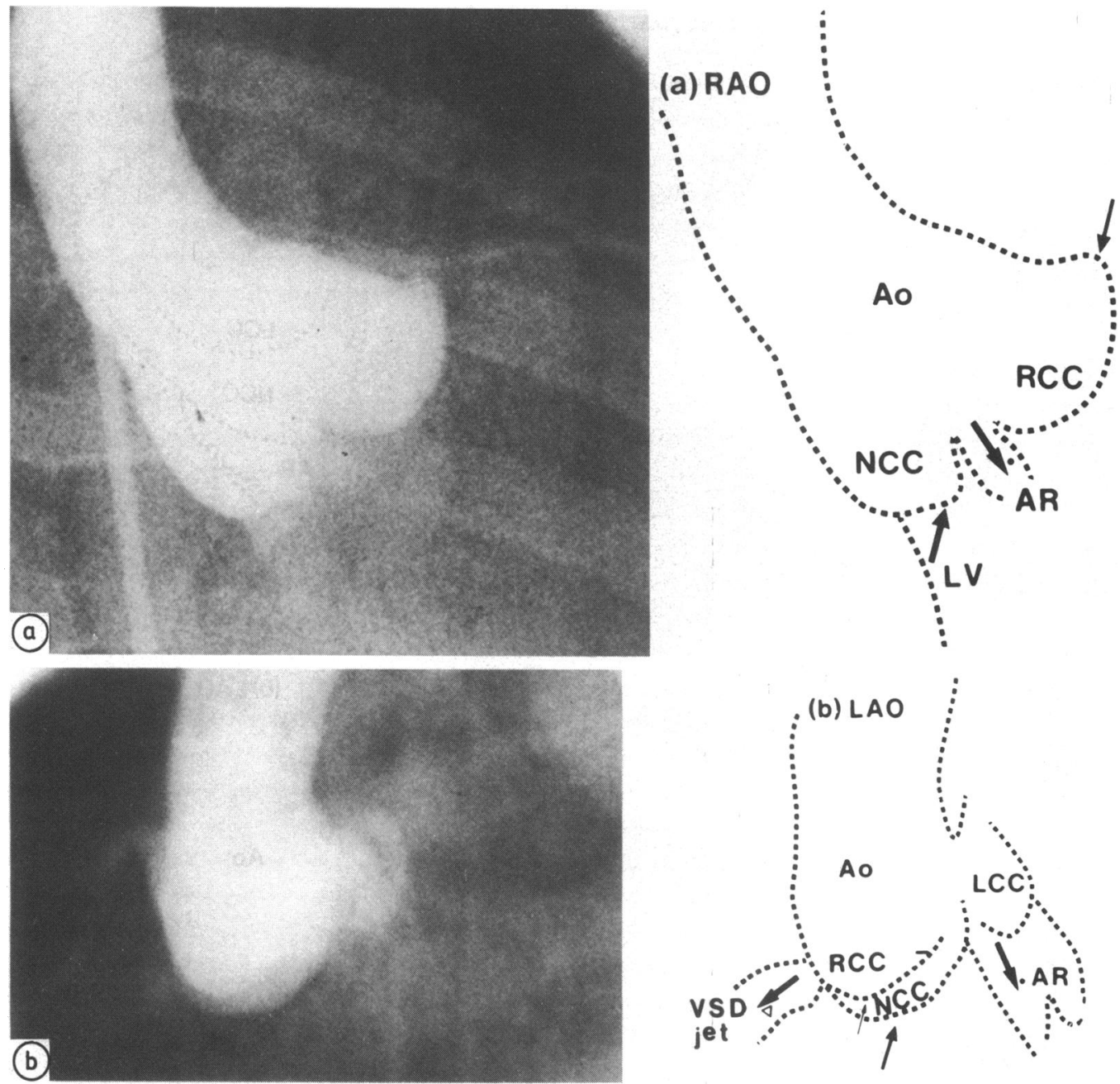

Fig 3 Aortogram showing moderate aortic prolapse (grade IIb) with aortic regurgitation in the right anterior oblique (a) and left anterior oblique (b) views. There is moderate deformity of one or more cusps (right and non-coronary cusps (arrows)) as a result of prolapse into ventricular septal defect and hence abnormal opening of the involved cusp (s). There is aortic regurgitation (arrow with dot), and dye outlines the ventricular septal defect (arrow with triangle). Ao, aorta; LCC, left coronary cusp; RCC, right coronary cusp; NCC, non-coronary cusp; $R A O$, right anterior oblique; $L A O$, left anterior oblique.

abnormal opening of the involved leaflet(s); aortic regurgitation present (fig 4).

The degree of aortic regurgitation was graded from 1 to 5 according to the criteria of Brandt et al. ${ }^{8}$ The degree of aortic valve prolapse was individually graded by three observers using the above criteria. If the gradings differed the aortograms were reviewed until a consensus was achieved.

\section{Results}

According to the angiographic criteria 18 patients of
Table 2 Grade of aortic valve prolapse and cusp( $s$ ) involved

\begin{tabular}{lcll}
\hline Grade of $A V P$ & $R C C$ & $N C C$ & $R C C+N C C$ \\
\hline II & 4 & - & - \\
IIa & 2 & 2 & 2 \\
IIb & $3^{\star}$ & 1 & 1 \\
III & $2^{\star}$ & 1 & $\frac{3}{11}$
\end{tabular}

^Includes a patient with infundibular ventricular septal defect. AVP, aortic valve prolapse; RCC, right coronary cusp; NCC, noncoronary cusp. 

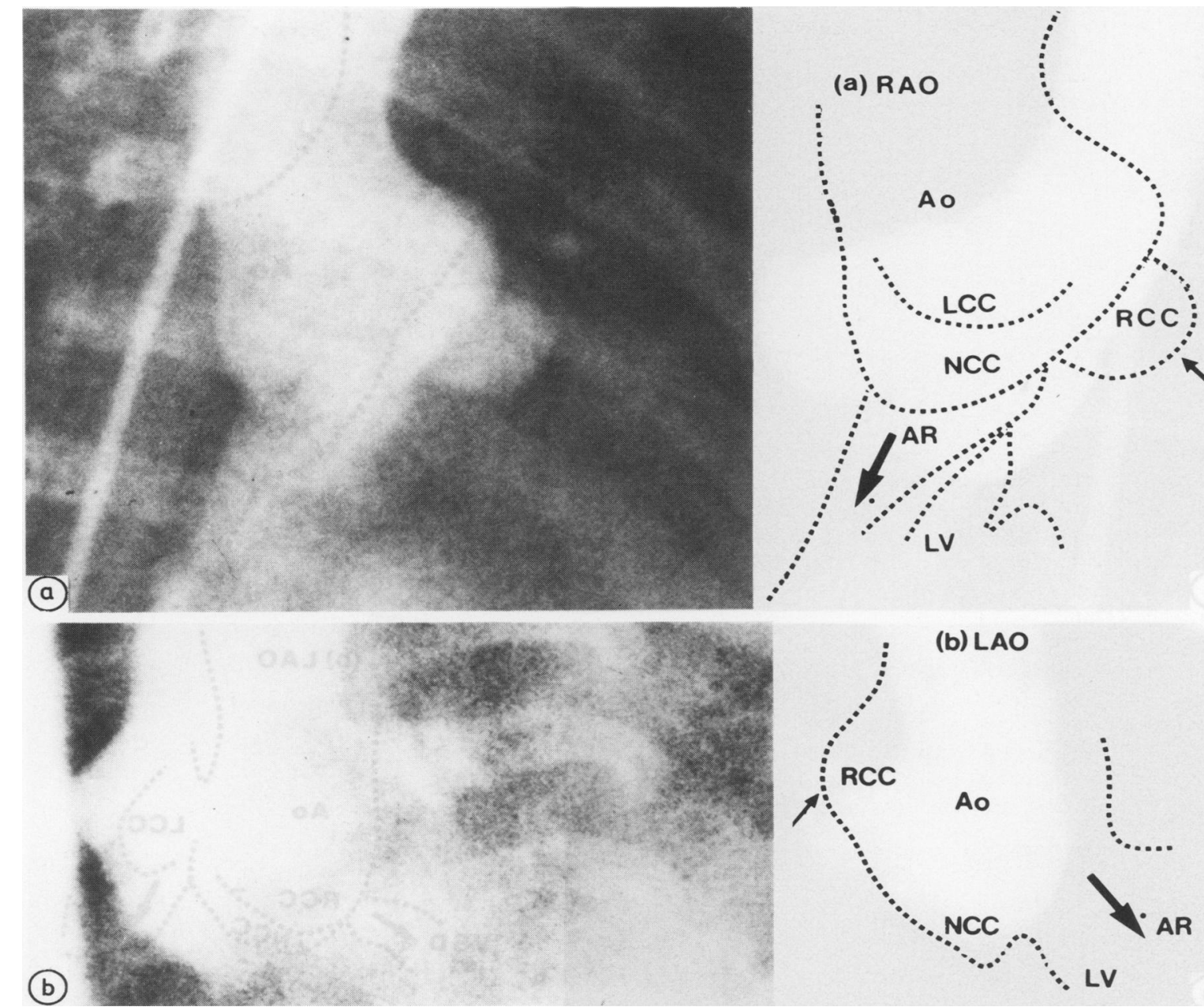

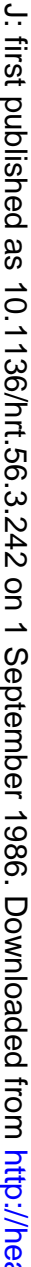

Fig 4 Aortogram showing severe aortic prolapse (grade III) in the right anterior oblique (a) and left anterior oblique (b) views. There is severe aortic valve deformity and one or more cusp(s) (right coronary cusp (arrow)) are apparently tethere్g to margin of ventricular septal defect and resultant abnormal opening of the involved leaflet (s). Aortic regurgitation is present (dotted arrow). Ao, aorta; LCC, left coronary cusp; RCC, right coronary cusp; NCC, non-coronary cusp; AR, aortic regurgitation; $L V$, left ventricle; $R A O$, right anterior oblique; $L A O$, left anterior oblique.

the 98 with ventricular septal defect were considered to have aortic valve prolapse (table 1 ). In these 18 patients the defect was infundibular in two patients and perimembranous in 16 , one of whom had an additional mid-muscular defect. Table 2 shows the details of cusp involvement and the degree of prolapse. None of the 16 patients with perimembranous defects and prolapse had an outlet extension.

In the total series there were five others with outlet extension without prolapse and a further two with infundibular defects without prolapse. Five of these seven patients were studied as infants.

Table 3 shows the pulmonary to systemic fow ratios (Qp:Qs). Two thirds of the patients withono prolapse and all patients with grade I aortic valve prolapse had a flow ratio $\geqslant 2 \cdot 0$. In patients with grade II aortic valve prolapse the mean ratio was $d .9$. Three patients with grade III aortic valve prolapse had a mean ratio of 1.5 . Only three patients hadian early diastolic murmur, even though eight Fad evidence of aortic regurgitation on aortography.

Of the 18 patients who had angiographic evidemce 
Table 3 Relation between the severity of aortic valve prolapse, pulmonary to systemic flow ratio, and the degree of aortic regurgitation

\begin{tabular}{|c|c|c|c|c|c|c|c|c|c|c|c|}
\hline \multirow{2}{*}{$\begin{array}{l}\text { Grade } \\
\text { of } A V P\end{array}$} & \multirow[b]{2}{*}{ No } & \multicolumn{3}{|c|}{ Pulmonary to systemic flow ratio } & \multirow[b]{2}{*}{$E D M$} & \multicolumn{6}{|c|}{ Angiographic $A R$} \\
\hline & & $<1.5$ & $1 \cdot 5-2$ & $>2$ & & 0 & 1 & 2 & 3 & 4 & 5 \\
\hline $\begin{array}{l}0 \\
\text { I } \\
\text { II } \\
\text { II } \\
\text { II } \\
\text { III }\end{array}$ & $\begin{array}{c}72 \dagger \\
4 \\
6 \\
5^{\star} \\
3^{\star}\end{array}$ & $\begin{array}{l}1 \star \\
1 *\end{array}$ & $\begin{array}{r}13 \\
4 \\
3 \\
2\end{array}$ & $\begin{array}{r}46 \\
4 \\
2 \\
1\end{array}$ & $\begin{array}{l}1^{\star} \\
2^{\star}\end{array}$ & $\begin{array}{l}4 \\
6\end{array}$ & 4 & & 1 * & & $1 \star$ \\
\hline
\end{tabular}

^Includes one patient with infundibular ventricular septal defect.

tExcludes five patients with postoperative residual ventricular septal defect and three with mild right ventricular outflow obstruction. AVP, aortic valve prolapse; EDM, early diastolic murmur; AR, aortic regurgitation.

Log-linear analysis showed that there was a significant inverse correlation between the degree of aortic valve prolapse and pulmonary to systemic flow ratio $(p<0.05) .^{16}$

of aortic valve prolapse, 14 had technically adequate echocardiograms. The echocardiogram suggested aortic valve prolapse in only eight. The features noted were generally seen in the long axis parasternal view of the left ventricle and aortic root. In this view the right coronary cusp and less commonly the non-coronary cusp appeared to be enlarged and bulbous (fig 5). Systolic motion of the affected leaflet was abnormal. The cusp appeared to be displaced inferiorly and not opening fully (fig 5 ). In the more severe cases of aortic valve prolapse the right coronary cusp could be seen prolapsing through the ventricular septal defect into the right ventricular outflow tract during diastole. In the short axis view also, the affected aortic valve leaflet could be seen bulging into the right ventricular outflow tract. If the non-coronary cusp was involved, it appeared to be bulbous and displaced the right coronary cusp anteriorly and towards the left (fig 6).

Thirteen of the patients diagnosed as having aortic valve prolapse have had surgical closure of the ventricular septal defect. The position of the ventricular septal defect was confirmed in all; two had infundibular defects and the others had perimembranous defects. Aortic valve prolapse was noted in all. In six patients the prolapsed aortic valve leaflet was tethered to the ventricular septal defect margin and had reduced the functional size of the
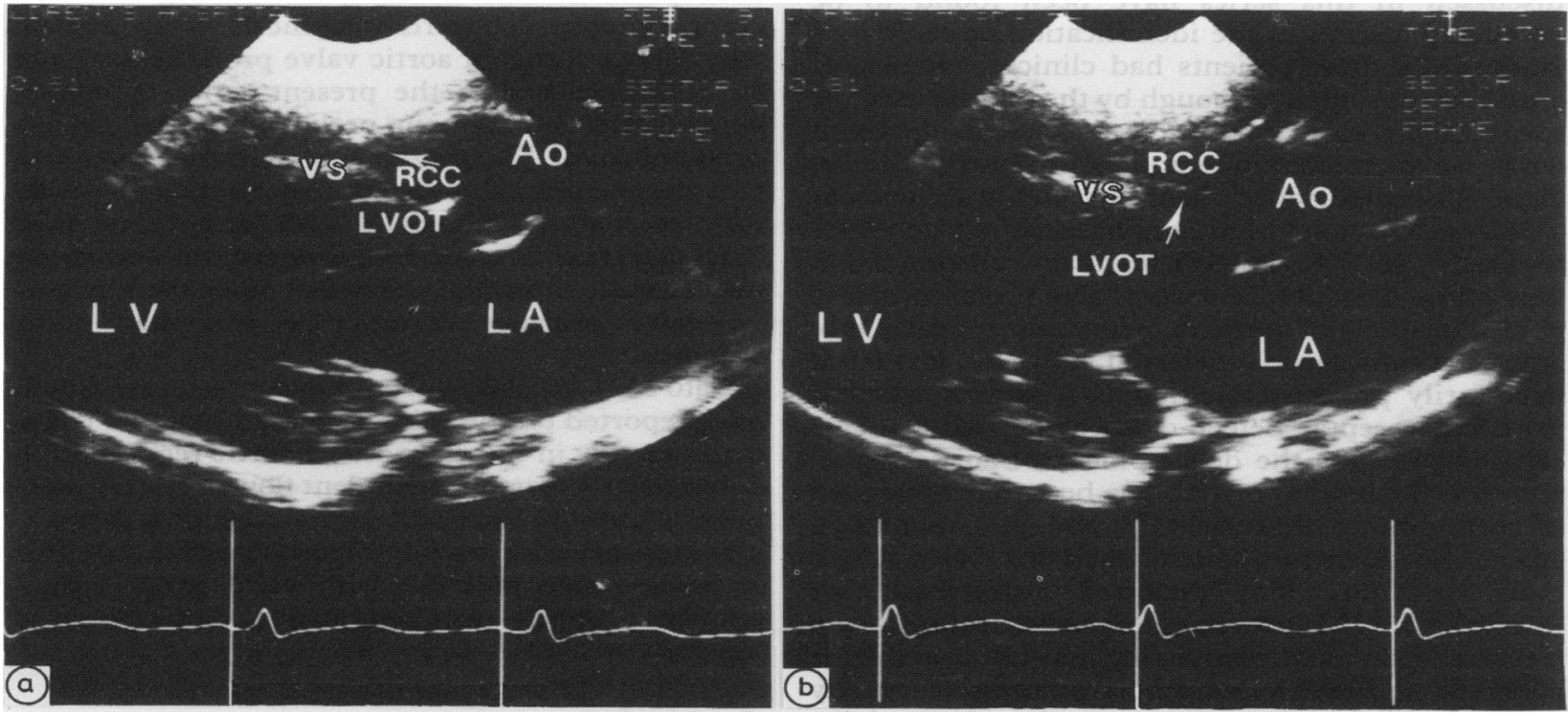

Fig 5 Parasternal long axis echocardiogram of child with aortic valve prolapse. (a) The right coronary cusp (RCC) appears enlarged and is prolapsing inferiorly into the ventricular septal defect (arrow). During systole (b) the affected cusp is opening completely (arrow). Ao, aorta; LVOT, left ventricular outflow tract; LV, left ventricle; VS, ventricular septum; RCC, right coronary cusp. 


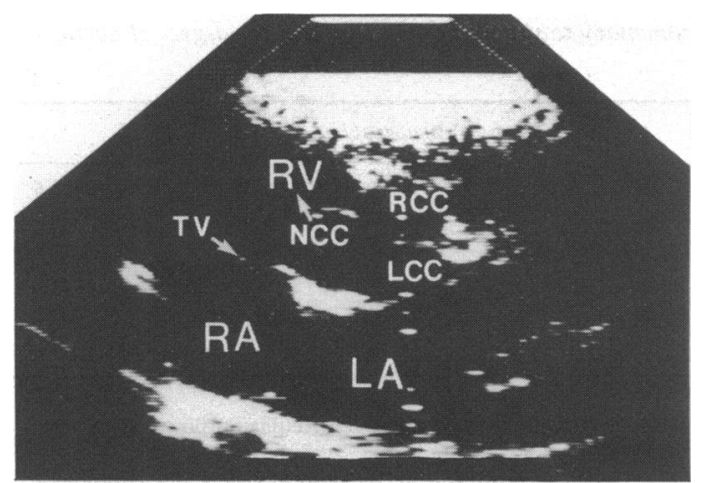

Fig 6 Short axis parasternal echocardiogram showing anterior protrusion of non-coronary cusp (top arrow). $R V$, right ventricle; $R A$, right atrium; $T V$, tricuspid valve; $L A$, left atrium; $R C C$, right coronary cusp; LCC, left coronary cusp; NCC, non-coronary cusp.

ventricular septal defect. An early diastolic murmur developed postoperatively in one patient.

\section{Discussion}

Others have attempted to classify aortic valve prolapse in ventricular septal defect, ${ }^{126}$ thereby drawing attention to an important complication of ventricular septal defect. The angiographic features discussed in this series have been found to be especially helpful in the identification of early prolapse. Only three patients had clinical evidence of aortic regurgitation, although by the criteria used for this study aortography showed some evidence of aortic valve prolapse in 18 and aortic regurgitation in eight. The importance of aortography in ventricular septal defect has been emphasised. ${ }^{134612}$ Aortography at the time of cardiac catheterisation may allow detection of aortic valve prolapse before clinical features of aortic regurgitation appear. Once aortic valve prolapse is detected, however, it will not necessarily progress. Neither is it known whether ventricular septal defect closure in such patients reliably prevents the development of aortic regurgitation. Such an approach has been recommended in infundibular defects, ${ }^{31213}$ and as prophylaxis against aortic regurgitation when the belly of the cusp is not too distorted, stretched, or thinned. ${ }^{241214}$ Plication of the valve leaflets and a Trusler repair ${ }^{4}$ of the valve ring may not prevent the progression of aortic regurgitation in more severely affected patients who may need early valve replacement.

Aortic valve prolapse provides a possible mechanism to explain the apparent spontaneous decrease in ventricular septal defect size accompanied by evidence of a decreasing left to right shunt. ${ }^{1315}$ In this study there was an inverse relation between the estimated degree of aortic valve prolapse and the pulmonary to systemic flow ratio $(p<0.05$ by log linear analysis $\left.{ }^{16}\right)$. Aortic valve prolapse may decrease ventricular septal defect size and aortography should be more widely applied to the investigation of ventricular septal defect. Only one of our infant group was shown to have aortic valve prolapse. Clinical evidence of aortic regurgitation is a relatively late sign and implies substantial prolapse.

Echocardiography was helpful only in more severe degrees of aortic valve prolapse. Previous reports have concentrated on aortic valve prolapse in infundibular septal defects. ${ }^{910}$ Ueda et al found that the aortic root size was increased in aortic valve prolapse. ${ }^{9}$ Their finding of systolic "semi-closure" of the aortic valve ${ }^{9}$ was observed in some of our subjects with more severe grades of aortic valve prolapse. With greater experience it may be possible to detect such incomplete opening of the affected cusp in many with milder degrees of prolapse, where the fulcrum for opening occurs lower down the belly of the affected cusp. Aziz et al were more successful in showing aortic valve prolapse in their patients with defects of the infundibular septum because the right coronary cusp was involved. ${ }^{10}$ They emphasised the importance of this investigation in the follow up of their patients. The difficulty in defining the noncoronary cusp echocardiographically may explain why milder forms of aortic valve prolapse were not as well visualised in the present series of mainly white patients in whom perimembranous defects predominated. The presence of an outlet extension to a perimembranous defect may suggest the need for further study, though the data did not show this. The detection of septal wall aneurysm formation may suggest closure of the defect other than by aortic valve prolapse though the two may occur together.

Sato et al, recording from the suprasternal notch, have reported on the value of pulsed Doppler echocardiography in the diagnosis of aortic regurgitation detected by a diastolic turbulent flow in the left ventricular outflow tract and in the ascending aorta. ${ }^{17}$ This advance may provide a more sensitive indicator of aortic valve prolapse with early aortic regurgitation. Doppler examination was not available in the current series.

\section{Conclusions}

The observed frequency of aortic valve prolapse in this series of unselected patients with ventricular 
septal defects indicates that aortography should be performed when patients with ventricular septal defect are catheterised. Spontaneous decrease in the size of a perimembranous or infundibular ventricular septal defect may be due to aortic valve prolapse even when aortic regurgitation is not evident clinically, and this raises the question of the need for catheterisation and aortography. This indication may be especially important in the older child. Cross sectional echocardiography in this series was only helpful in the identification of more severe aortic valve prolapse.

\section{References}

1 Van Praagh R, McNamara JJ. Anatomic types of ventricular septal defect with aortic insufficiency. Diagnostic and surgical considerations. Am Heart $\mathfrak{f}$ 1968;75:604-19.

2 Tatsuno K, Konno S, Ando M, Sakakibara S. Pathogenetic mechanisms of prolapsing aortic valve and aortic regurgitation associated with ventricular septal defect. Anatomical, angiographic and surgical considerations. Circulation 1973;48:1028-37.

3 Momma K, Toyama K, Takao A, et al. Natural history of subarterial infundibular ventricular septal defect. Am Heart $\mathcal{F}$ 1984;108:1312-7.

4 Trusler GA, Moes CAF, Kidd BSL. Repair of ventricular septal defect with aortic insufficiency. $f$ Thorac Cardiovasc Surg 1975;66:394-402.

5 Nadas AS, Thilenius OG, LaFarge CG, Hauck AJ. Ventricular septal defect with aortic regurgitation. Medical and pathologic aspects. Circulation 1964; 29:862-73.

6 Tatsuno K, Konno S, Sakakibara S. Ventricular septal defect with aortic insufficiency. Angiocardiographic aspects and a new classification. Am Heart $\mathcal{f}$
1973;85:13-21.

7 Corone P, Dayon F, Gaudeau S, et al. Natural history of ventricular septal defect. A study involving 790 cases. Circulation 1977;55:908-15.

8 Brandt PWT, Roche AHG, Barratt-Boyes BG, Lowe JB. Radiology of homograft aortic valves. Thorax 1969;24:129-41.

9 Ueda T, Nishioka K, Mikawa H, et al. Echocardiographic evaluation of aortic cusp prolapse in children with ventricular septal defect. Fpn Circ $\mathcal{F}$ 1983; 47:1359-67.

10 Aziz KU, Cole RB, Paul MH. Echocardiographic features of supracristal ventricular septal defect with prolapsed aortic valve leaflet. $\mathrm{Am} \mathcal{F}$ Cardiol 1979;43:854-9.

11 Keane TF, Plauth WH, Nadas AS. Ventricular septal defect with aortic regurgitation. Circulation 1977; 56(suppl 1):72-7.

12 Tatsuno K, Ando M, Takao A, Hatsune K, Konno S. Diagnostic importance of aortography in conal ventricular-septal defect. Am Heart $\mathcal{F}$ 1975;89:171-7.

13 Puliese G, Luisi VS, Santi C, Eufrate S. Ventricular septal defect associated with aortic regurgitation. Surgical consideration. G Ital Cardiol 1982; 12:46-51.

14 Somerville J, Brandao A, Ross DN. Aortic regurgitation with ventricular septal defect. Surgical management and clinical features. Circulation 1970;41: 317-30.

15 Anderson RH, Lenox CC, Zuberbuhler JR. Mechanisms of closure of perimembranous ventricular septal defect. Am $\mathcal{F}$ Cardiol 1983;52:341-5.

16 Cox DR. The analysis of binary data. London: Methuen, 1970.

17 Sato Y, Okishima T, Matsuoka Y, Yama Moto K, Sennari $\mathrm{E}$, Hayakawa $\mathrm{K}$. A study of aortic regurgitation with conal ventricular septal defect by means of pulsed Doppler echocardiography. $f$ Cardogr 1982;12:257-65. 